\title{
Interactions between gall bladder bile and mucosa; relevance to gall stone formation
}

\author{
M R Jacyna
}

Over 300 years ago, Diemerbroek appreciated that bile enters the gall bladder to 'acquire greater strength and digestive power', ${ }^{1}$ and since then many studies have increased our knowledge of its functions. Understanding the gall bladder and its interaction with the biliary contents is important, because the gall bladder plays a crucial role in the formation of gall stones; most gall stones develop within the gall bladder, and removal of the gall bladder cures the tendency to form further stones in most, though not all, instances. Although cholesterol saturated bile originating in the liver (so called 'lithogenic' bile) is a prerequisite for gall stone development, ${ }^{2}$ lithogenic bile is also frequently found in normal individuals. ${ }^{3}$ Consequently there must be other factors within the bile or mucosa of the gall bladder which determine why gall stones develop in some patients with lithogenic bile but not others.

One of these factors may be the concentration of calcium within the gall bladder bile. Studies have now shown that gall bladder bile from patients with either cholesterol or pigment stones is frequently super saturated with calcium and thus liable to calcium precipitation. ${ }^{4}$ Most gall stones contain a central core of calcium salts $^{56}$ around which layers of either cholesterol or calcium bilirubinate are deposited as the stone enlarges. ${ }^{5}$ This suggests that calcium precipitation may be the critical initiating factor for gall stone development. Supporting evidence for this is seen in studies which show that feeding modest amounts of calcium to animals increases the biliary calcium concentration and also promotes the risk of gall stone formation. ${ }^{7}$ The concentration of calcium within the gall bladder lumen appears to be the critical determinant, and lowering the intraluminal calcium concentration by úsing amiloride (which reduces the concentrating ability of the gall bladder mucosa $)^{89}$ reduces the incidence of stone formation in these animals. ${ }^{9}$ As well as being physically incorporated into gall stones during their formation, biliary calcium ions also reduce the solubility of biliary cholesterol, ${ }^{10}$ making cholesterol crystal formation (nucleation) and deposition into stones more likely. Biliary calcium ions also stimulate mucus glycoprotein secretion by the gall bladder mucosa ${ }^{11}$ and this effect can be blocked by calcium antagonists. Other studies have suggested that the mucus glycoproteins found in bile may be responsible for the precipitation of biliary calcium ${ }^{1213}$; thus the calcium within the gall bladder bile, by stimulating mucus production, may be indirectly responsible for its own precipitation.

Mucus itself has long been recognised as a factor that plays a role in gall stone development. ${ }^{14}$ In animals fed a lithogenic diet, mucus hypersecretion by the mucosa precedes cholesterol crystal and stone formation, ${ }^{15}$ and patients with gall stones have increased levels of mucus degradation products in bile compared with non-lithogenic controls. ${ }^{16}$ Secretion of mucus by the gall bladder mucosa into the bile, as previously mentioned, may be stimulated by calcium ions, ${ }^{11}$ but also by prostaglandins. ${ }^{141718}$

The prostaglandins may also be of relevance to the formation of gall stones. As well as being potent mucus secretagogues, they have other important effects on gall bladder mucosal function ${ }^{19}$; they reduce sodium and water absorption by the mucosa ${ }^{20}$ and initiate fluid and electrolyte secretion into the gall bladder lumen, ${ }^{21}$ both of which will tend to result in a less concentrated gall bladder bile. They also stimulate gall bladder motility. ${ }^{22}$ Normally, there is a basal release of prostaglandins by the gall bladder mucosa and this can be enhanced by luminal lysophosphatidyl choline, gall bladder distension or experimental cholecystitis. ${ }^{23}$ Cholesterol given to animals (which causes gall stones to form) results in an increased synthesis of prostaglandins by the gall bladder mucosa ${ }^{18}$ and subsequently of mucus secretion into the bile. ${ }^{15}$ Recent studies have suggested that treatment with non-steroidal anti-inflammatory drugs (NSAID's - which are prostaglandin antagonists) may inhibit cholesterol precipitation and crystal formation in man, ${ }^{24}$ and may also prevent stone formation in the gall bladders of animals ${ }^{25}$ and $\operatorname{man}^{26}$ at high risk of cholelithiasis. The link between prostaglandins and gall stone formation may be through mucus secretion, and NSAID's may protect against gall stone formation by blocking prostaglandin induced mucus release and consequent biliary calcium precipitation.

Between periods of digestion the resting gall bladder stores bile, and concentrates the stored bile through the active absorption of sodium $(\mathrm{Na}+)$ and the passive absorption of water. ${ }^{27}$ In chronic cholecystitis, however, as gall bladders become progressively more diseased, there is a corresponding reduction in concentrating ability by the mucosa. ${ }^{2829}$ This is the result of a 'functional' failure of electrolyte and water
St Mary's Hospital,

M R Jacyna

Correspondence to: Dr M R Jacyna, Dep Northwick Park Hospital,

Watford Road, Harrow, London HAl 3UJ.

Accepted for publication 10 August 1989 
absorption ${ }^{30}$ and also an active fluid and $\mathrm{Na}+$ secretion. ${ }^{31}$ It is likely that the fluid secretion in these inflamed gall bladders is mediated by prostaglandins, as it can be reversed to the more usual absorption by NSAIDs. ${ }^{312}$ The effects of prostaglandins, on motility and fluid absorption in the human gall bladder, are believed to be mediated through intramural nerves, ${ }^{33}$ and there is some evidence that endogenous opiates may act as a feedback control by blocking the prostaglandin effects. ${ }^{34}$

Although prostaglandins are involved in mediating physiological and pathophysiological changes in the gall bladder, the lipid content of the bile may also be an important determinant of gall bladder function. Studies have now shown that during the early stages of cholesterol gall stone formation, before gall stones have actually formed, there is an increase in water and electrolyte absorption by the gall bladder. ${ }^{35}$ Further studies have suggested that it is the increased lipid content of the bile during this early phase of lithogenesis which determines these alterations in ion transport across the gall bladder mucosa. ${ }^{36}$ Lithogenic bile contains increased amounts of cholesterol and phospholipids, and consequently has a higher phospholipid to bile salt ratio, ${ }^{35} 36$ which significantly alters ionic mucosal transport. ${ }^{36}$ The gall bladder mucosae of animals ${ }^{37}$ and man $^{38} 39$ also normally absorbs cholesterol from the bile and will absorb more cholesterol from biles containing larger amounts of cholesterol. ${ }^{38}$ When inflamed, however, there is a secretion of cholesterol from the mucosa into the gall bladder lumen. ${ }^{38}$ Changes in mucosal cell membrane cholesterol content as a result of increased cholesterol absorption from lithogenic biles ${ }^{39}$ will be associated with changes in cellular membrane fluidity and function ${ }^{40}$ that may be responsible for the alterations in mucosal function seen in the early stages of gall stone formation.

The gall bladder, however, has evolved several of its own defence mechanisms against gall stones forming, which revolve around its ability to absorb and secrete various substances. First, the mucosa acidifies bile by secreting hydrogen ions $(\mathrm{H}+)^{41}$ which causes a fall in biliary $\mathrm{pH}$ that will reduce the likelihood of calcium precipitation within the gall bladder lumen ${ }^{41}$ and thus the initiation of gall stones. Biliary acidification appears to be extremely important in preventing calcium precipitation ${ }^{42}$ and one study has suggested that gall stone formation in some patients may be caused by a specific defective mucosal $\mathrm{H}+$ secretion in spite of a relatively normal gall bladder concentrating ability.$^{43}$ Second, the gall bladder absorbs large amounts $(50 \%)$ of calcium from the bile, ${ }^{44}$ which reduces the intraluminal free $\mathrm{Ca}++$ content and thus the risk of calcium precipitation within bile, by mucin or other nucleating factors. Third, during periods of digestion, there is active secretion of electrolytes and water into the gall bladder lumen. ${ }^{45}$ The hormone secretin may be partly responsible for this secretory effect, ${ }^{46}$ which will have an intermittent diluting effect on the biliary contents and may also help to 'wash out' particulate matter and 'sludge' from the gall bladder which may otherwise act as a nidus for stone formation. Lastly, antinucleating factors that inhibit choles- terol $^{47}$ and calcium ${ }^{42}$ precipitation, are found in the bile (although it is not clear whether the gall bladder mucosa or liver actually secretes them) and may also help to reduce the risk of gall stones developing.

Gall stones are still a major cause of morbidity in man. In the United Kingdom, about 20\% of the population may expect to develop cholelithiasis at some time ${ }^{48}$ and cholecystectomy is now the most common elective abdominal operation performed in Western countries. In high risk patients, therapeutic manipulation of the mucosal or biliary factors that predispose to gall stone formation (such as mucosal prostaglandins, biliary mucus, calcium content and $\mathrm{pH}$ ) may eventually allow the possibility of prevention of gall stone formation.

1 Diemerbroek I. Anatome corporis humani. Utrecht: 1672

2 Admirand WH, Small DM. The physicochemical basis of cholesterol gallstone formation in man. $\mathcal{F}$ Clin Invest 1968; 47: 1043-52.

3 Holzbach RT, Marsh M, Olszweski M, Holan K. Cholesterol solubility in bile. Evidence that supersaturated bile is frequent in healthy man. $\mathcal{F}$ Clin Invest $1973 ; 52$ : 1467-79.

4 Shiffman ML, Moore EW. Bile is supersaturated with calcium in most patients with cholesterol and mixed gallstones in most patients with cholesterol and mix

5 Bean JM, Bills PM, Lewis D. Microstructure of gallstones. Gastroenterology 1979; 76: 548-55.

6 Pitchumoni CS, Viswanathan KV, Moore EW. Analysis and localisation of elements in human cholesterol gallstones: calcium and other elements are present in the central nidus region [Abstract]. Gastroenterology 1987; 92: A1764.

7 Magnuson TH, Lillemoe KD, Peoples GE, Pitt HA. Oral calcium promotes pigment gallstone formation. $\mathcal{F}$ Surg Res 1989; 46: 286-91.

8 Abedin MZ, Roslyn JJ, Abdou MS, et al. Ion transport in the prairie dog gallbladder [Abstract]. Fed Proc 1987; 46: 1081

9 Strichartz SD, Abedin MZ, Abdou MS, Roslyn JJ. The effects of amiloride on biliary calcium and cholesterol gallstone formation. Ann Surg 1989; 209: 152-6.

10 Neithercut WD. Effect of calcium, magnesium and sodium ions on in vitro nucleation of human gallbladder bile. Gut 1989; 30: 665-70.

11 Malet PF, Locke CL, Trotman BW, Soloway RD. The calcium ionophore A23187 stimulates glycoprotein secretion by the guinea-pig gallbladder. Hepatology 1986; 6: 569-73.

12 Maki T, Matsushiro T, Suzuki N, et al. Role of sulfated glycoproteins in gallstone formation. Surg Gynecol Obstet 1971; 132: 846-51.

13 Nagashima H, Suzuki N, Yosizawa Z. Coagulating effect of calcium carbonate on sulfated glycoproteins isolated from pathological human bile. Tohoku $\mathcal{F}$ Exp Med 1974; 113: 15968

14 LaMont JT, Smith BF, Moore JRL. Role of gallbladder mucin in pathophysiology of gallstones. Hepatology 1984; 4: 51-6.

15 Lee SP, LaMont T, Carey MC. Role of gallbladder mucus hypersecretion in the evolution of cholesterol gallstones Studies in the prairie dog. $\mathcal{F}$ Clin Invest 1981; 67: 1712-23.

16 Bouchier IAD, Cooperbrand SR, El Kodsi BM. Mucus souchier IAD, Cooperbrand SR, El Kodsi BM. Mucus
substances and viscosity of normal and pathologic bile. Gastroenterology 1965; 49: 343-5.

17 Wahlin T, Thornell E, Jivegard L, Svanvik J. Effects of intraluminal prostaglandin E2 in vivo on secretory behaviour and ultrastructural changes in mouse gallbladder epithelium. Gastroenterology 1988; 95: 1632-5.

18 LaMorte WW, LaMont JT, Hale W, Booker ML, Scott TE, Turner B. Gallbladder prostaglandins and lysophospholipids as mediators of mucin secretion during cholelithiasis. Am ₹ Physiol 1986; 251: 701-9.

19 Wood JR, Svanvik J. Gall-bladder water and electrolyte transport and its regulation. Gut 1983; 24: 579-93.

20 Leyssac $P$, Bukhave K, Frederiksen $\mathrm{O}$. Inhibitory effect of prostaglandins on isosmotic fluid transport by rabbit gallbladder in vitro, and its modification by blockade of endogenous PGE-biosynthesis by indomethacin. Acta Physiol Scand 1974; 92: 496-507.

21 Heintze K, Goetz R, Koerlings H, Wood JR. Characterisation of the prostaglandin induced secretion in the isolated gallbladder of guinea pig. Naunyn Scmiedebergs Arch 1976; gallbladder of guin

22 Thornell E, Svanvik J, Wood JR. Effects of intraarterial PGE-2 on gallbladder fluid transport, motility and hepatic bile flow in the cat. Scand $\mathcal{F}$ Gastroenterol 1981; 16: 1083-8.

23 Thornell E, Jivegard L, Bukhave K, Rask-Madsen J, Svanvik J. Prostaglandin E2 formation by the gallbladder in experimental cholecvstitis. Gut 1986; 27: 370-373.

24 Broomfield P, Chopra R, Sheinbaum R, et al. Formation and prevention of lithogenic bile and gallstones during weight loss [Abstract]. Gastroenterology 1987; 92: 1721.

25 Lee SP, Carey MC, LaMont JT. Aspirin prevention of cholesterol gallstone formation in prairie dogs. Science 1981; 211: 1429-30. 
26 Hood K, Gleeson D, Ruppin DC, Dowling RH. Prevention of gallstone recurrence by non-steroidal anti-inflammatory drugs. Lancet 1988; ii: 1223-5.

27 Rose RC. Absorptive functions of the gallbladder. In: Johnson LR, ed. Physiology of the gastrointestinal tract. New York: Raven Press, 1981: 1021-33.

28 Radberg G, Jivegard L, Friman S, Zettergern L, Svanvik J. Relationship between gallbladder histopathology and ability Relationship between gallbladder histopathology and ability to concentrate biliar

29 Jacyna MR, Ross PE, Hopwood D, Bouchier IAD. Studies on the mechanism of non-visualisation of diseased human gallbladders during oral cholecystography. Postgrad Med $\mathcal{F}$ 1988; 64: 931-4.

30 Nahrwold DL, Rose RC, Ward SP. Abnormalities in gallbladder morphology and function in patients with cholecystitis. Ann Surg 1976; 184: 415-21.

31 Svanvik J, Thornell E, Zettergren L. Gallbladder function in experimental cholecystitis; reversal of the inflammatory net fluid secretion into the gallbladder by indomethacin. Surgery $1981 ; 89: 500-6$

32 Jacyna MR, Ross PE, Hopwood DH, Bouchier IAD. Sodium Transport in the diseased human gallbladder and the effects of indomethacin. Clin Sci 1988; 75: 147-9.

33 Lundgren O, Svanvik J, Jivegard L. Enteric Nervous System II. Physiology and pathophysiology of the gallbladder. Dig Dis Sci 1989; 34: 284-8.

34 Jivegard L, Thornell E, Bjorck S, Svanvik J. The effects of morphine and enkephaline on gallbladder function in experimental cholecystitis; inhibition of inflammatory gallbladder secretion. Scand . F Gastroenterol 1985; 20: 1049-56.

35 Conter RL, Roslyn JL, Porter-Fink V, DenBesten L. Gallbladder absorption increases during early cholesterol gallstone formation. Am J Surg 1986; 151: 184-91.

36 Roslyn JL, Abedin MZ, Strichartz SD, Abdou MS, Palant CE. Regulation of gallbladder ion transport: role of biliary lipids. Surgery 1989; 105: 207-12.
37 Neiderhiser DH, Harmon CK, Roth PH. Absorption of cholesterol by the gallbladder. F Lipid Res 1976; 17: 117-24.

38 Svanvik J, Pellegrini CA, Allen B, Bernhoft R, Way LW. Transport of fluid and biliary lipids in the canine gallbladder in experimental cholecystitis. $\mathcal{F}$ Surg Res $1986 ; 41: 425-31$.

39 Jacyna MR, Ross PE, Bakar MA, Hopwood D, Bouchier IAD. Characteristics of cholesterol absorption by human gallbladder: relevance to cholesterolosis. $\mathcal{F}$ Clin Pathol $1987 ; 40$. 524-9.

40 Chapman D, Kramers MTC, Restall CJ. Cholesterol and biomembrane structure. In: Danielsson $\mathrm{H}$, Sjovell J, eds. Sterols and bile acids. Amsterdam: Elsevier, 1985: 159.

41 Rege RV, Moore EW. Evidence for $\mathrm{H}+$ secretion by the in vivo canine gallbladder. Gastroenterology 1987; 92: 281-9.

42 Rege VR, Dawes LG, Moore EW. Canine common duct and gallbladder bile contain antinucleating factors that inhibit $\mathrm{CaCO}_{3}$ precipitation. $\mathcal{F}$ L ab Clin Med 1989; 113: 642-50.

43 Shiffman ML, Moore EW. Gallbladder mucosal function in patients with cholelithiasis; dissociation between concentrating ability and $\mathrm{H}+$ ion secretion [Abstract]. Gastroenterology 1987; 92: A1775.

44 Rege RV, Nahrwold DL, Moore EW. Absorption of biliary calcium from the canine gallbladder; Protection against the formation of calcium-containing gallstones. $\mathcal{F}$ Lab Clin Med 1987; 110: $381-6$.

45 Svanvik J, Allen B, Pellegrini C, Way L. Variations in the concentrating function of the gallbladder in the conscious concentrating function of the gallbladder

46 Jacyna MR, Ross PE, Hopwood DH, Bouchier IAD. Effects of Secretin on sodium ion transport in the human gallbladder. Aliment Pharmacol Therap 1989; 3: 293-7.

47 Holzbach RT, Kibe A, Thiel E, Howell JH, Marsh M Herman RE. Biliary proteins. Unique inhibitors of cholesterol crystal nucleation in human gallbladder bile. F Clin Invest 1984; 73: 35-47.

48 Barker DJP, Gardner MJ, Power C, Hutt MSR. Prevalence of gallstones at necropsy in nine British towns. Br Med f 1979; ii: $1389-92$. 